\title{
Comparative genomic hybridization indicating two distinct subgroups of pilocytic astrocytomas
}

\author{
Janusz Szymas, M.D., Ph.D., Gunther Wolf, Ph.D., Simone Petersen, Ph.D., Karsten \\ Schluens, Ph.D., Stanislaw NowaK, M.D., PH.D., and IVer Petersen, M.D., PH.D.
}

Departments of Pathology and Neurosurgery, University of Medical Sciences, Poznan, Poland; and Institute of Pathology, University-Hospital Charite, Berlin, Germany

Object. The authors investigated the spectrum of chromosomal imbalances of pilocytic astrocytoma by using comparative genomic hybridization $(\mathrm{CGH})$.

Methods. Tumor DNA was extracted from surgically obtained samples of 18 pilocytic astrocytomas that were examined for the presence of neoplastic tissue on frozen sections. Comparative genomic hybridization was performed using standard procedures, and digital image analysis was conducted using out by custom-made software. The chromosomal alterations were determined by a statistical procedure in which Student's t-test (99\% confidence interval) was used. Details on CGH analysis and individual ratio profiles are available at http://amba.charite.de/cgh/.

Conclusions. The results suggests the presence of two distinct genetic subgroups of pilocytic astrocytoma, with imbalances of chromosome 19 being the major change for differentiation. In the first group ( 10 samples), deletions on chromosome 19 were shown as well as multiple gains mainly on chromosomes 5 and $6 \mathrm{q}$ but also on chromosomes 4 , $7,8,10$, and 11 . The second group (eight samples) was characterized by overrepresentation on chromosomes 19p and $22 \mathrm{q}$, which were associated with deletions on $4 \mathrm{q}, 5 \mathrm{q}, 6 \mathrm{q}, 9 \mathrm{p}, 13 \mathrm{q}$, and 18q. To understand the diverse biological and clinical behavior exhibited by this tumor type, it is important that pilocytic astrocytomas be classified into distinct subgroups according to their genetic makeup.

\section{KEY WORDS - pilocytic astrocytoma - DNA • comparative genomic hybridization •} chromosome 19

Pilocytic astrocytomas occur most frequently in children and young adults. Although most pilocytic astrocytomas affect the cerebellum, they also show a predilection for the optic nerves and chiasm, as well as for the hypothalamus. Less often affected are the cerebral hemispheres or the spinal cord. The occurrence of supratentorial pilocytic astrocytomas remains uncommon in children and rare in adults. ${ }^{1,5,12,15}$ Although, macroscopically, pilocytic astrocytomas are well circumscribed, in some tumors parenchymal infiltration and invasion of leptomeninges $^{8,18,25,32,34,35,39,42}$ or even the nuchal musculature has been shown. ${ }^{22}$ A very small proportion of pilocytic astrocytomas ( $<1 \%$ of cases) do show histological features of anaplastic progression. After the patient undergoes radiotherapy, this incidence has been observed to rise to $1.8 \%$; however, the percentage still remains relatively low. ${ }^{52}$ This correlates with the observation that 70 to $90 \%$ of patients experience long-term survival after surgery. ${ }^{10}$ Although

Abbreviations used in this paper: $\mathrm{CI}=$ confidence interval; $\mathrm{CGH}=$ comparative genomic hybridization; duTP $=$ deoxyuridine triphosphate; GFAP = glial fibrillary acidic protein. many tumors are indolent and potentially curable, there is a distinct probability that the tumor may recur even after a very long latency period of up to five decades. ${ }^{24,61}$ Based on histological features, some authors have differentiated between two distinct group of patients with "excellent" and "moderately good" prognoses. ${ }^{14,16,17,27,50,60}$

There are no consistent genetic aberrations know to characterize pilocytic astrocytomas. ${ }^{9,40}$ Although cytogenetic analysis of this most benign variant of astrocytoma has revealed the presence of normal karyotypes in the majority of cases it is notable that Thiel, et al., ${ }^{49}$ have observed that in two of eight tumors they studied there was loss of the sex chromosome and tandem associations between different chromosomes. In one case there was a 46, XY, inv(9) karyotype. Moreover, White, at al., ${ }^{59}$ and Zattara-Cannoni, et al., ${ }^{63}$ have observed that one third of pilocytic astrocytomas were characterized by chromosomal gains, most commonly chromosomes 7, 8, and 11, suggesting that trisomy 7 and 8 are relatively common events in pilocytic astrocytomas.

In the present study, we investigated the spectrum of chromosomal imbalances found in pilocytic astrocytomas 
by performing $\mathrm{CGH}$, which suggested the presence of two distinct genetic subgroups.

\section{MATERIAL AND METHODS}

\section{Clinical and Pathological Data}

The 18 pilocytic astrocytomas included in the present study were surgical specimens obtained in the Neurosurgical Department, University of Medical Sciences of Poznan. At the time of surgery six patients were in the pediatric-age group, and the other 12 patients, except for one, were young adults. The mean age of the patients at the time of surgery was 23 years (range 6-48 years). The sex ratio was almost equal: 10 female and eight male patients. Ten tumors were of cerebellar and six were of supratentorial location, whereas two were optic gliomas. Except in one case, all samples were obtained from primary tumors. The specimen obtained in Case 15 (lab no. 15168 ) originated from a tumor that recurred after the patient underwent radiotherapy following the first surgery. The clinicopathological data are summarized in Table 1. All tumors were classified according to the World Health Organization grading system. ${ }^{23}$

\section{Histological Examination}

Surgically removed tumor tissue samples were immediately fixed in $4 \%$ formalin in $0.1 \mathrm{M}$ phosphate buffer, $\mathrm{pH}$ 7.4, dehydrated in absolute ethanol, and embedded in paraffin. For light microscopy, $4-\mu \mathrm{m}$ sections were stained with hematoxylin and eosin, Masson's trichrome, and the periodic acid Schiff method.

Immunohistochemical studies were conducted using paraffin-embedded sections and a peroxidase-antiperoxidase method in which we used commercially available

TABLE 1

Clinicopathological data obtained in patients with pilocytic astrocytoma classified into two subgroups

\begin{tabular}{|c|c|c|c|}
\hline $\begin{array}{l}\text { Case } \\
\text { No. }\end{array}$ & $\begin{array}{l}\text { Age (yrs), } \\
\text { Sex }\end{array}$ & Diagnosis & Localization \\
\hline \multicolumn{4}{|c|}{ group w/ pronounced gains } \\
\hline 1 & $14, \mathrm{~F}$ & pilocytic astrocytoma & suprasellar \\
\hline 2 & $22, \mathrm{M}$ & pilocytic astrocytoma & cerebellum \\
\hline 3 & $32, \mathrm{~F}$ & pilocytic astrocytoma & frontocentral \\
\hline 4 & $16, \mathrm{~F}$ & pilocytic astrocytoma & cerebellum \\
\hline 5 & $38, \mathrm{M}$ & pilocytic astrocytoma & $\begin{array}{l}\text { thalamus \& } 3 \mathrm{rd} \\
\text { ventricle }\end{array}$ \\
\hline 6 & $27, \mathrm{M}$ & pilocytic astrocytoma & central \\
\hline 7 & $16, \mathrm{~F}$ & pilocytic astrocytoma & cerebellum \\
\hline 8 & $21, \mathrm{M}$ & pilocytic astrocytoma & cerebellum \\
\hline 9 & $19, \mathrm{~F}$ & pilocytic astrocytoma & cerebellum \\
\hline 10 & $19, \mathrm{~F}$ & pilocytic astrocytoma & cerebellum \\
\hline \multicolumn{4}{|c|}{ group w/ multiple losses } \\
\hline 11 & $29, \mathrm{~F}$ & $\begin{array}{l}\text { pilocytic astrocytoma } \\
\text { (optic glioma) }\end{array}$ & opticus \\
\hline 12 & $48, \mathrm{M}$ & pilocytic astrocytoma & central \\
\hline 13 & $37, \mathrm{M}$ & pilocytic astrocytoma & frontocentral \\
\hline 14 & $6, \mathrm{M}$ & pilocytic astrocytoma & cerebellum \\
\hline 15 & $15, \mathrm{~F}$ & pilocytic astrocytoma & cerebellum \\
\hline 16 & $11, \mathrm{M}$ & pilocytic astrocytoma & cerebellum \\
\hline 17 & $23, \mathrm{~F}$ & $\begin{array}{l}\text { pilocytic astrocytoma } \\
\text { (optic glioma) }\end{array}$ & opticus \\
\hline 18 & $21, \mathrm{~F}$ & pilocytic astrocytoma & cerebellum \\
\hline
\end{tabular}

monoclonal and polyclonal antibodies. We investigated the following antigens: GFAP, HNK-1, A2B5, S-100, and vimentin. Tissue sections were pretreated in a wet autoclave for antigen retrieval.

\section{Comparative Genomic Hybridization Analysis}

Tumor DNA was extracted from samples obtained during surgery. The samples were verified for the presence of a high amount of tumor tissue by the intraoperative frozen section diagnosis and, if necessary, were trimmed to reduce normal contamination prior to freezing and storing in liquid nitrogen. Comparative genomic hybridization preparation and digital image analysis were performed as previously described. ${ }^{36,43}$ Detailed information on the CGH procedure is available at our web site: http://amba. charite.de/cgh/. Briefly, $5 \mu \mathrm{g}$ each of tumor DNA and normal reference DNA obtained from the peripheral blood lymphocytes of a healthy female donor were labeled with biotin-16-dUTP and digoxigenin-11-dUTP, respectively, by standard nick translation. Then $1 \mu \mathrm{g}$ of tumor and normal DNA together with human Cot1 DNA were hybridized to slides with normal chromosome metaphase spreads, which were either prepared from peripheral blood lymphocytes or commercially purchased. After 3 days of hybridization at $37^{\circ} \mathrm{C}$, the tumor and normal DNA samples were visualized using fluorescein and rhodamine, respectively.

The fluorescence images were captured as 12-bit gray level images by using a fluorescence microscope and a cooled charged-coupled device camera connected to a Macintosh Quadra 950. Image processing was conducted using custom-made CGH software that is based on other karyotyping software written in a Windows 95 version of the image software AMBA. The software was implemented on a 400-MHz Pentium II PC running Microsoft Windows 95 . The mean ratio profiles were determined from the analysis of at least 10 metaphases. Analysis was accomplished by a procedure that automatically detects chromosomal aberrations based on the average ratio profiles with the use of Student's distribution function, 1.0: 1.0 thresholds and the $99 \%$ and/or $95 \%$ CI. ${ }^{37,38}$

\section{Sources of Supplies and Equipment}

The monoclonal antibodies were obtained from DAKO (Glostrup, Denmark) and the polyclonal antibodies from Becton-Dickinson (Mountain View, CA). The biotin-16dUTP was purchased from Böhringer Mannheim (Mannheim, Germany), as was the digoxigenin-11-dUTP. The peripheral blood lymphocytes were bought from Vysis (Downers Grove, IL). The fluorescence microscope (Axiphot) was aquired from Carl Zeiss (Thornwood, NY) and the charged-coupled software device camera from Photometrics (Tucson, AZ). Our karyotyping software is based on that (KARYOTYP) produced by IBSB GmbH (Berlin, Germany).

\section{RESULTS}

\section{Light Microscopy}

The characteristic biphasic pattern was observed in almost every tumor. In the more solid portions of the tumor, piloid cells were arranged in bundles, whereas stellate 


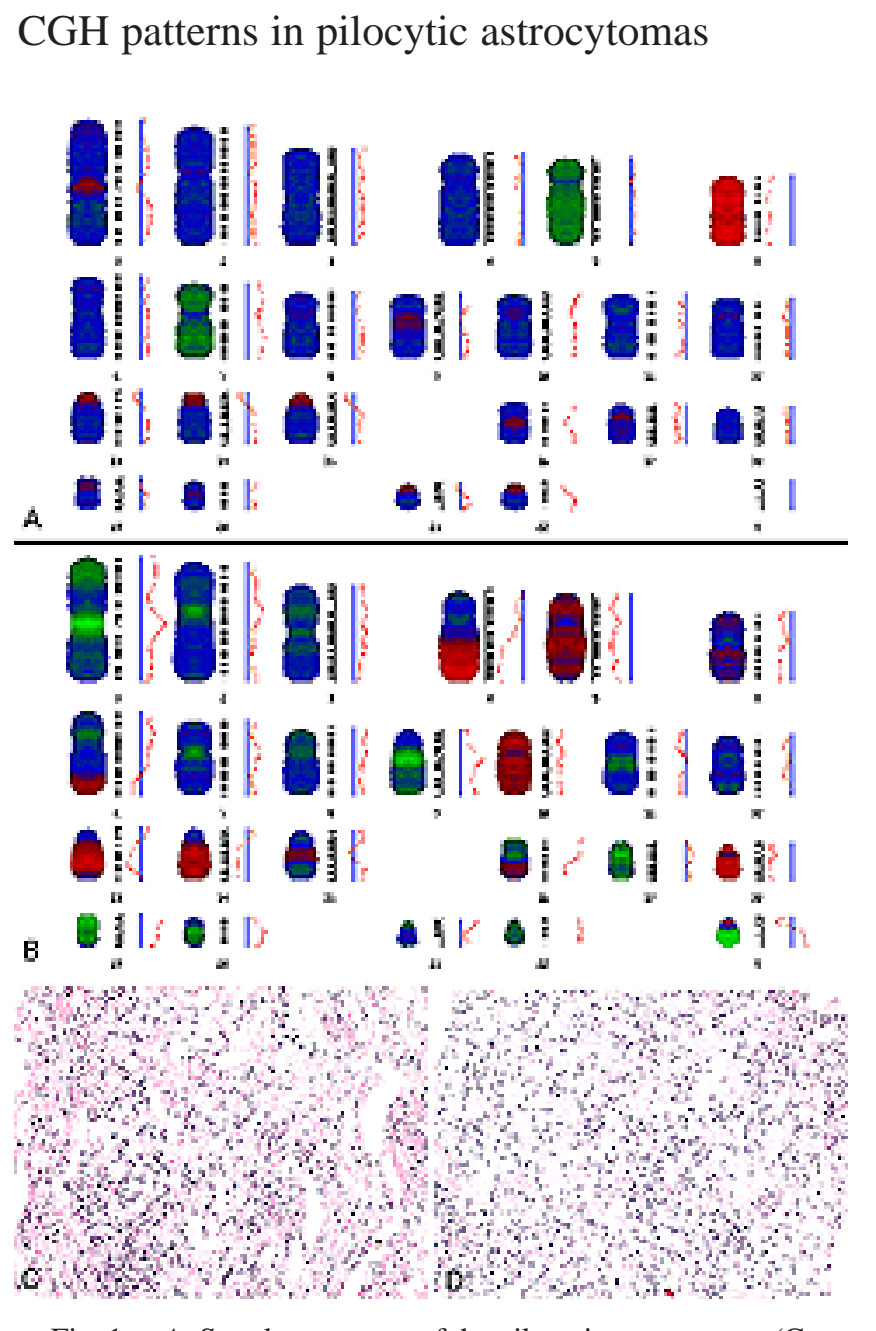

Fig. 1. A: Sum karyograms of the pilocytic astrocytoma (Case 2) seen in Fig $1 C$. Deletions are depicted in red, amplifications in green, and equilibrium between the tumor and normal DNA in blue. Changes include losses on chromosomes 9q13-q21, 13q12 14q11.2-q12, and 19p13.1-p13.2 and gains on chromosomes 1q24q32, 2q22-q24, 3p14, 4q26-q27, 4q31.1-q31.2, 5, 7p11.2-p21, 7q, 8q12-q21.3, 9p21, 10p14-pter, 10q21-q22, 10q24, 11q22-q23, 13q21-q22, 15q15-q21, and 15q25. The red curves depict the average ratio profiles. For each chromosome, the middle green line corresponds to the normal state (fluorescence ratio 1.0). The blue line of the tumor rells escence ratio 0.75 ). The blue line on the right represents a trisomy in $50 \%$ of the tumor cells of an otherwise diploid tumor (fluorescence ratio 1.25) $B$ : Sum karyograms of the pilocytic astrocytoma (Case 14) seen in Fig. $1 D$. Deletions are depicted in red, amplifications in green and equilibrium between the tumor and normal DNA in blue. Changes include losses on chromosomes 4q24-qter, 5p15.2-q34, 6q22-qter, 10, 13q12-q33, 14q, 15q15-q22, 16q13-q24, and 18 and amplifications on chromosomes 1p31-pter, 1p13-q25, 2p16-p21, 2p11.2q21, 3p13-p21, 3p12-q23, 4p16, 6p21.3-q12, 7q11.2, 8p22-pter, 8p12-q11.2, 9p12-q34, 11q12-q14, 15q24-q25, 16p, 17, 19p13.3$\mathrm{q} 13.3,20 \mathrm{p} 11.2-\mathrm{q} 13.3$, and 22q11.2-q13. C: Photomicrograph showing the somewhat loose pattern of solid area of pilocytic astrocytoma consisting of elongated, fibrillated cells (Case 2). H \& $\mathrm{E}$, original magnific original magnification $\times 100$. D: Photomicrograph showing the compact, paucicellular region of pilocytic astrocytoma consisting of elongated and highly fibrillated cells (Case 14 ). $\mathrm{H} \& \mathrm{E}$, original magnification $\times 100$ cells formed loose-textured tissue, often with microcystic changes. These textures was associated with Rosenthal fibers and granular bodies, respectively.

\section{Immunohistochemical Reaction}

Neoplastic astrocytes with long hairlike extensions were stained strongly with GFAP, HNK-1, S-100, and vimentin and did not stain for A2B5. The reaction of cells in the looser, microcystic or spongy areas were weaker with antibodies to GFAP.

\section{Frozen Section Analysis}

For all genetic molecular studies, neoplastic material was confirmed by light microscopic analysis of the frozen sections. If present, tissue from adjacent brain was removed in all cases. Thus, dilution effects by normal tissue contamination can be largely excluded in this study.

\section{Comparative Genomic Hybridization Analysis}

The CGH sum karyogram and the ratio profile with its 99\% CI were mainly used to define the chromosomal imbalances found in each tumor (Fig. 1).

The spectrum of imbalances is exemplified by the two $\mathrm{CGH}$ results depicted in Fig. 1 in one tumor (Case 2). Whereas in one tumor (Fig. $1 A$ ) there were only a few imbalances, in the second one (Case 14; Fig. $1 B$ ) the multiple and pronounced changes resembled a highly malignant astrocytoma. Histological and immunohistochemical analyses in both cases, however, revealed typical features of pilocytic astrocytoma as shown in Fig. $1 C$ and $D$. These two cases represent the spectrum of changes found in pilocytic astrcytoma. The pattern of the first tumor subtype was observed in the majority of cases. Individual profiles as well as sum profiles, line representations, and histograms obtained in the tumor group can be viewed at our CGH online tumor database (http://amba. charite.de/cgh/).

When we used histograms to describe the overall genetic changes, we were able to distinguish two subgroups of pilocytic astrocytoma. The first, which we called the "group with multiple gains," represented 10 of the 18 cases. The typical changes observed in this group were multiple gains mainly on chromosomes 5 and 6 but also on chromosomes $4,7,8,10$, and 11. In addition we observed deletions on chromosome 19 as well as DNA losses on chromosome 22 . The histogram indicated (99\% CI) overrepresentation with peak incidences at $5 \mathrm{p} 12,5 \mathrm{q} 23$, and $5 \mathrm{q} 31$ in nine of 10 cases and $6 \mathrm{q} 23$ in eight of 10 cases and losses at 19p13.1 (Fig. 2 upper and lower).

The second (eight cases) was called the "group with multiple losses." These tumors were associated with various multiple losses predominantly on chromosomes 3, 4, $5,6 q, 7 p, 9 p, 10 q, 13 q, 14 q, 17$, and 18. In contrast to the group characterized by multiple gains, in these cases overrepresentations were most frequently found on chromosomes 19 and gains on chromosomes 16, 17, and 22q (Fig. 2 center and lower). The histogram indicated the highest frequency of changes for the losses on 4q24, 5q14-21, $6 \mathrm{q} 12,9 \mathrm{p} 21-2$, and $13 \mathrm{q} 21$ in six of eight cases, as well as the overrepresentation at $19 \mathrm{p} 13.3$-centr and $19 \mathrm{q} 13.1$ in six 


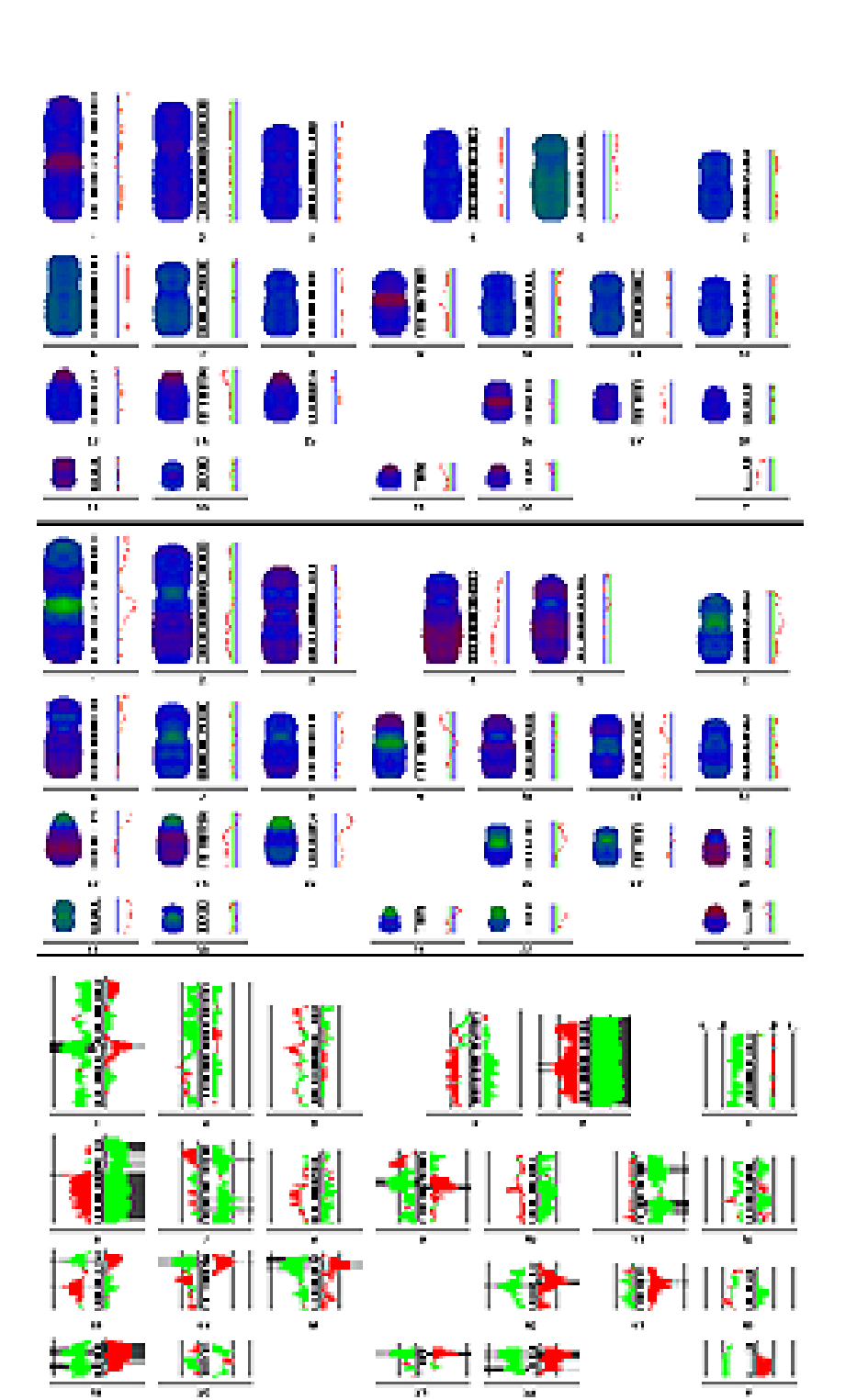

Fig. 2. Upper: Super karyograms of the chromosomal imbalances detected in the group of 10 pilocytic astrocytomas with ances cected in the gith gains on chromosomes 5 and $6 \mathrm{q}$ and Center: Super karyograms of the chromosomal imbalances detected in the group of eight pilocytic astrocytomas with prominen losses. Typical changes visible in this group and include the DNA losses on chromosomes 4q, 5, 6q, 13 q, and 18q and gains on chromosome 19. Lower: Difference histograms of two subgroups of pilocytical astrocytoma represented in the upper and center supe karyograms. The left side of each histogram shows the genetic losses, and the right side shows the genetic gains. The three black lines on both sides of a histogram represent the $0 \%$ (closest to the ideogram), the $50 \%$, and the $100 \%$ (farthest from the ideogram) relative frequency levels. The percentage of changes only occurring in the tumor subgroup with prominent gains is shown in green. The excess of changes in the second group with multiple losses is shown in red. The blank areas beneath the colored regions indicate the percentage of changes in both groups. Light gray and dark gray peaks refer to chromosomal locations where the difference between tumor groups are statistically significant at the $5 \%$ and $1 \%$ significance level according to the results of Chi-squa $1 \%$ significance level according to the results of Chi-square analyosomes 5,6 , and 19 . of eight, and 22q11.1-2 in seven of eight cases. The dichotomy between both tumor subgroups is most clearly visible in the difference histogram presented in Fig. 2 lower.

When we considered subgroups according to the topographic localization of the tumor (cerebellar compared with supratentorial), patients age (in childhood as compared with adult blood), or sex, no preferential gains or osses were observed.

\section{DISCUSSION}

Investigations of genetic changes in neuroectodermal tumors have already led to a fairly good characterization of several tumor types of the central nervous system such diffuse astrocytomas, ${ }^{13,21,31,57}$ oligodendrogliomas, ${ }^{2}$ oligoastrocytomas, ${ }^{26,29}$ ependymomas, ${ }^{11}$ medulloblastomas ${ }^{30}$ and menigiomas. ${ }^{58}$ In contrast, the genetic abnormalities of the many benign tumors such pilocytic astrocytoma have remained largely enigmatic. However, understanding of these tumors may be especially important to understand the early carcinogenesis of astrocytic tumors.

In the present study we investigated, for the first time, pilocytic astrocytomas by using $\mathrm{CGH}$, and the results indicated the presence of two distinct genetic subtypes. Interestingly, the single major change that distinguishes these two subsets are DNA imbalances on chromosome. ${ }^{19}$ This chromosome has been identified as playing an important role in astrocytoma tumorigenesis. ${ }^{44,56}$ An extensive allelotyping study of gliomas revealed loss of heterozygosity in almost every astrocytoma subtype: three of 19 World Health Organization Grade II tumors, 12 of 27 anaplastic astrocytomas, 16 of 76 glioblastomas multiforme, four of nine oligodendrogliomas, three of five anaplastic oligodendrogliomas, five of nine mixed oligoastrocytomas, and eight of 10 anaplastic oligoastrocytomas. ${ }^{57}$ The fact that chromosome 19-related data obtained from studying pilocytic astrocytoma are still inconclusive is most probably related to our observation that distinct genetic subtypes exist.

One group of tumors was characterized by deletions on chromosomes 19 and 22 and frequent overrepresentations of chromosomes 5 and 6 as well as chromosomes 4, 7, 8, 10 , and 11. In this regard, it is interesting to note that numerical gains on chromosomes 7, 8, and 11 have already been detected in cytogenetic studies, ${ }^{59,63}$ whereas deletions on chromosome $22 \mathrm{q}$, as detected using allelotyping, have recently been described in astrocytoma. ${ }^{21}$ The analysis of candidate genes found on chromosome 19 such as $B A X$, $M I A$, and ANOVA has not shown conclusive evidence of tumor suppressor properties. $4,7,54$

The second subgroup of pilocytic astrocytomas was characterized by gains on chromosome 19 , deletions at $4 \mathrm{q}$, $5 q, 6 q, 9 p 13 q$, and 18q, and gains of 22q. High-copy amplifications on chromosome 19 in human malignant gliomas were observed by Schrock, et al. ${ }^{47}$ This change has been mainly associated with glioma tumor progression as well as lung carcinoma. ${ }^{8,41,46,51}$ In this regard, it is important to note that amplifications are not typically found in pilocytic astrocytoma. Instead more often we observed numerical chromosome gains or low-level overrepresenta- 
tions except for single cases (see Fig. 2), which may represent the tumor subset that will be characterized by recurrence and/or tumor progression. Follow-up information about our tumor collective will be available in the future. Again, still lacking is conclusive evidence for a role of the many protooncogenes that reside on chromosome 19 such as AKT2, BCL-3, ${ }^{6}$ RRAS, ${ }^{28,53}$ HKR1, HKR $2,{ }^{33}$ FOSB, ${ }^{20,48}$ and $J U N B^{62}$ in the development of astrocytic tumors.

Consistent with previous findings, a certain percentage of cases carried deletions on chromosome 9p, which has also been found by allelotyping, although the role of the p16 gene is still unknown. ${ }^{55}$ Chromosome 9p deletions have also been described in previous CGH studies as being found in low and high malignant diffuse astrocytoma and glioblastoma. ${ }^{3,31,45}$ However, for other chromosomes, their CGH patterns differ from pilocytic astrocytomas. The fact that we observed, infrequently, deletions on chromosome $17 \mathrm{p}$ might corroborate the finding that the $p 53$ gene is rarely mutated in pilocytic astrocytomas, although this view has recently been challenged. ${ }^{19}$ Regardless, p53 mutation does not seem to be associated with gross chromosomal deletions.

The existence of genetic subtypes of pilocytic astrocytoma is corroborated by clinicopathological studies that succeeded in differentiating subgroups of patients with excellent and moderate prognosis. However, we were not able to recognize specific morphological features that may characterize the two genetic subtypes, and this may be related to the limited number of cases analyzed to date.

In summary, our study revealed that pilocytic astrocytoma is characterized by two distinct genetic subgroups We believe that this is an important finding, although it raises many questions. For example, which genes are affected by the chromosomal imbalances with importance for the tumor biology? How are the genetic alterations related to the clinical outcome? Are there any morphological or immunohistochemical markers that might be used to differentiate these tumor subgroups? We hope to answer these questions in future studies.

\section{References}

1. Biczysko W, Szymas J, Gabryel P: [Ultrastructural characteristics of pilocytic astrocytoma in children and adolescents.] Neuropatol Pol 21:81-94, $1983(\mathrm{Pol})$

2. Bigner SH, Matthews MR, Rasheed BK, et al: Molecular genetic aspects of oligodendrogliomas including analysis by comparative genomic hybridization. Am J Pathol 155:375-386, 1999

3. Bigner SH, Schrock E: Molecular cytogenetics of brain tumors. J Neuropathol Exp Neurol 56:1173-1181, 1997

4. Bosserhoff AK, Hein R, Bogdahn U, et al: Structure and promoter analysis of the gene encoding the human melanoma-inhibiting protein MIA. J Biol Chem 271:490-495, 1996

5. Burger PC, Paulus W, Kleihues P: Pilocytic astrocytoma, in Kleihues P, Cavenee WK (eds): Pathology and Genetics of Tumours of the Nervous System. Lyon: International Agency for Research on Cancer, 1997, pp 19-33

6. Cheng JQ, Ruggeri B, Klein WM, et al: Amplification of AKT2 in human pancreatic cells and inhibition of AKT2 expression and tumorigenicity by antisense RNA. Proc Natl Acad Sci USA 93:3636-3641, 1996

7. Chou D, Miyashita T, Mohrenweiser HW, et al: The BAX gene maps to the glioma candidate region at $19 \mathrm{q} 13.3$, but is not altered in human gliomas. Cancer Genet Cytogenet 88: 136-140, 1996

8. Civitello LA, Packer RJ, Rorke LB, et al: Leptomeningeal dissemination of low-grade gliomas in childhood. Neurology 38 : $562-566,1988$

9. Collins VP: Gliomas. Cancer Surv 32:37-51, 1998

10. Dirven CM, Mooij JJ, Molenaar WM: Cerebellar pilocytic astrocytoma: a treatment protocol based upon analysis of 73 cases and a review of the literature. Childs Nerv Syst 13:17-23, 1997

11. Ebert C, von Haken M, Meyer-Puttlitz B, et al: Molecular genetic analysis of ependymal tumors. NF2 mutations and chromosome 22q loss occur preferentially in intramedullary spinal ependymomas. Am J Pathol 155:627-632, 1999

12. Forsyth PA, Shaw EG, Scheithauer BW, et al: Supratentorial pilocytic astrocytomas. A clinicopathologic, prognostic, and flow cytometric study of 51 patients. Cancer 72:1335-1342, 1993

13. Fujisawa H, Kurrer M, Reis RM, et al: Acquisition of the glioblastoma phenotype during astrocytoma progression is associated with loss of heterozygosity on 10q25-qter. Am J Pathol 155:387-394, 1999

14. Fulchiero A, Winston K, Leviton A, et al: Secular trends of cerebellar gliomas in children. J Natl Cancer Inst 58:839-843, 1977

15. Garcia DM, Fulling KH: Juvenile pilocytic astrocytoma of the cerebrum in adults. A distinctive neoplasm with favorable prognosis. J Neurosurg 63:382-386, 1985

16. Gilles FH, Winston K, Fulchiero A, et al: Histologic features and observational variation in cerebellar gliomas in children. $\mathbf{J}$ Natl Cancer Inst 58:175-181, 1977

17. Gjerris F, Klinken L: Long-term prognosis in children with benign cerebellar astrocytoma. J Neurosurg 49:179-184, 1978

18. Grabb PA, Albright AL, Pang D: Dissemination of supratentorial malignant gliomas via the cerebrospinal fluid in children. Neurosurgery 30:64-71, 1992

19. Hayes VM, Dirven CM, Dam A, et al: High frequency of TP53 mutations in juvenile pilocytic astrocytomas indicates role of TP53 in the development of these tumors. Brain Pathol 9: 463-467, 1999

20. Herdegen T, Leah JD: Inducible and constitutive transcription factors in the mammalian nervous system: control of gene expression by Jun, Fos and Krox, and CREB/ATF proteins. Brain Res Brain Res Rev 28:370-490, 1998

21. Ino Y, Silver JS, Blazejewski L, Nishikawa R, et al: Common regions of deletion on chromosome 22q12.3-q13.1 and 22q13.2 in human astrocytomas appear related to malignancy grade. J Neuropathol Exp Neurol 58:881-885, 1999

22. Kepes JJ, Lewis RC, Vergara GG: Cerebellar astrocytoma invading the musculature and soft tissues of the neck. Case report. J Neurosurg 52:414-418, 1980

23. Kleihues P, Burger PC, Scheithauer BW: Histological Typing of Tumours of the Central Nervous System, ed 2. Berlin: Springer-Verlag, 1993

24. Kleinman GM, Schoene WC, Walshe TM III, et al: Malignant transformation in benign cerebellar astrocytoma. Case report. J Neurosurg 49:111-118, 1978

25. Kocks W, Kalff R, Reinhardt V, et al: Spinal metastasis of pilocytic astrocytoma of the chiasma opticum. Childs Nerv Syst 5:118-120, 1989

26. Kraus JA, Koopmann J, Kaskel P, et al: Shared allelic losses on chromosomes $1 \mathrm{p}$ and $19 \mathrm{q}$ suggest a common origin of oligodendroglioma and oligoastrocytoma. J Neuropathol Exp Neurol 54:91-95, 1995

27. Leviton A, Fulchiero A, Gilles FH, et al: Survival status of children with cerebellar gliomas. J Neurosurg 48:29-33, 1978

28. Lowe DG, Capon DJ, Delwart E, et al: Structure of the human and murine R-ras genes, novel genes closely related to ras protooncogenes. Cell 48:137-146, 1987

29. Maintz D, Fiedler K, Koopmann J, et al: Molecular genetic evi- 
dence for subtypes of oligoastrocytomas. J Neuropathol Exp Neurol 56:1098-1104, 1997

30. Nishizaki T, Harada K, Kubota H, et al: Genetic alterations in pediatric medulloblastoma detected by comparative genomic hybridization. Pediatr Neurosurg 31:27-32, 1999

31. Nishizaki T, Ozaki S, Harada K, et al: Investigation of genetic alterations associated with the grade of astrocytic tumor by comparative genomic hybridization. Genes Chromosomes Cancer 21:340-346, 1998

32. Obana WG, Cogen PH, Davis RL, et al: Metastatic juvenile pilocytic astrocytoma. Case report. J Neurosurg 75:972-975, 199

33. Oguri T, Katoh O, Takahashi T, et al: The Kruppel-type zinc finger family gene, HKR1, is induced in lung cancer by exposure to platinum drugs. Gene 222:61-67, 1998

34. Patt S, Haberland N, Graupner H, et al: May 1999-16 year old male with an unexpected MRI finding. Brain Pathol 9: 743-744, 1999

35. Perez MJ, Lorenzo G, Munoz A, et al: Low grade disseminated astrocytoma in childhood. Rev Neurol 25:877-881, 1997

36. Petersen I, Bujard M, Petersen S, et al: Patterns of chromosomal imbalances in adenocarcinoma and squamous cell carcinoma of the lung. Cancer Res 57:2331-2335, 1997

37. Petersen I, Langreck H, Wolf G, et al: Small-cell lung cancer is characterized by a high incidence of deletions on chromosome 3p, 4q, 5q, 10q, 13q and 17p. Br J Cancer 75:79-86, 1997

38. Petersen S, Aninat-Meyer M, Schlüns K, et al: Chromosomal alterations in the clonal evolution to the metastatic stage of squamous cell carcinomas of the lung. Br J Cancer 82:65-73, 2000

39. Pollack IF, Hurtt M, Pang D, et al: Dissemination of low grade intracranial astrocytomas in children. Cancer 73:2869-2878, 1994

40. Ransom DT, Ritland SR, Kimmel DW, et al: Cytogenetic and loss of heterozygosity studies in ependymomas, pilocytic astrocytomas, and oligodendrogliomas. Genes Chromosomes Cancer 5:348-356, 1992

41. Ried T, Petersen I, Holtgreve-Grez H, et al: Mapping of multiple DNA gains and losses in primary small cell lung carcinomas by comparative genomic hybridization. Cancer Res $\mathbf{5 4}$ : 1801-1806, 1994

42. Romeike BFM, Niedermayer I, Braun-Fischer A, et al: Pilocytic astrocytoma (PA) with subarachnoidal dissemination an "Fahr"-like calcifications after brain irradiation and polychemotherapy. Clin Neuropathol 16:282-283, 1997

43. Roth K, Wolf G, Dietel M, et al: Image analysis for comparative genomic hybridization based on a karyotyping program for windows. Anal Quant Cytol Histol 19:461-474, 1997

44. Rubio MP, Correa KM, Ueki K, et al: The putative glioma tumor suppressor gene on chromosome $19 \mathrm{q}$ maps between APOC2 and HRC. Cancer Res 54: 4760-4763, 199

45. Sallinen SL, Sallinen P, Haapasalo H, et al: Accumulation of genetic changes is associated with poor prognosis in grade II astrocytomas. Am J Pathol 151:1799-807, 1997

46. Schlegel J, Scherthan H, Arens N, et al: Detection of complex genetic alterations in human glioblastoma multiforme using comparative genomic hybridization. J Neuropathol Exp Neurol 55:81-87, 1996

47. Schrock E, Thiel G, Lozanova T, et al: Comparative genomic hybridization of human malignant gliomas reveals multiple am- plification sites and nonrandom chromosomal gains and losses. Am J Pathol 144:1203-1218, 1994

48. Siderovski DP, Blum S, Forsdyke RE, et al: A set of human putative lymphocyte G0/G1 switch genes includes genes homologous to rodent cytokine and zinc finger protein-encoding genes. DNA Cell Biol 9:579-587, 1990

49. Thiel G, Losanowa T, Kintzel D, et al: Karyotypes in 90 human gliomas. Cancer Genet Cytogenet 58:109-120, 1992

50. Tihan T, Fisher PG, Kepner JL, et al: Pediatric astrocytomas with monomorphous pilomyxoid features and a less favorable outcome. J Neuropathol Exp Neurol 58:1061-1068, 1999

51. Tognon M, Casalone R, Martini F, et al: Large T antigen coding sequences of two DNA tumor viruses, BK and SV40, and nonrandom chromosome changes in two glioblastoma cell lines. Cancer Genet Cytogenet 90:17-23, 1996

52. Tomlinson FH, Scheithauer BW, Hayostek CJ, et al: The significance of atypia and histologic malignancy in pilocytic astrocytoma of the cerebellum: a clinicopathologic and flow cytometric study. J Child Neurol 9:301-310, 1994

53. Tsutsumi M, Tsujiuchi $T$, Ishikawa $\mathrm{O}$, et al: Increased telomerase activities in human pancreatic duct adenocarcinomas. Jpn J Cancer Res 88:971-976, 1997

54. Ueki K, Ramaswamy S, Billings SJ, et al: Chromosomal localization to 19q13.3, partial genomic structure and 5' cDNA sequence of the human symplekin gene. Somat Cell Mol Genet 23:229-231, 1997

55. Ueki K, Rubio MP, Ramesh V, et al: MTS1/CDKN2 gene mutations are rare in primary human astrocytomas with allelic loss of chromosome 9p. Hum Mol Genet 3:1841-1845, 1994

56. von Deimling A, Louis DN, von Ammon K, et al: Evidence of a tumor suppressor gene on chromosome $19 \mathrm{q}$ associated with human astrocytomas, oligodendrogliomas, and mixed gliomas. Cancer Res 52:4277-4279, 1992

57. von Deimling A, Nagel J, Bender B, et al: Deletion mapping of chromosome 19 in human gliomas. Int J Cancer 57:676-680, 1994

58. Weber RG, Bostrom J, Wolter M, et al: Analysis of genomic alterations in benign, atypical, and anaplastic meningiomas: toward a genetic model of meningioma progression. Proc Natl ward Sci USA 94:14719-14724, 1997

59. White FV, Anthony DC, Yunis EJ, et al: Nonrandom chromosomal gains in pilocytic astrocytomas of childhood. Hum Pathol 26:979-986, 1995

60. Winston K, Gilles FH, Leviton A, et al: Cerebellar gliomas in children. J Natl Cancer Inst 58:833-838, 1977

61. Wisoff HS, Llena JF: Glioblastoma multiforme of the cerebellum five decades after irradiation of a cerebellar tumor. J Neurooncol 7:339-344, 1989

62. Woodgate A, Walton M, MacGibbon GA, et al: Inducible transcription factor expression in a cell culture model of apoptosis. Brain Res Mol Brain Res 66:211-216, 1999

63. Zattara-Cannoni H, Gambarelli D, Lena G, et al: Are juvenile pilocytic astrocytomas benign tumors? A cytogenetic study in 24 cases. Cancer Genet Cytogenet 104:157-160, 1998

\section{Manuscript received February 14, 2000.}

Accepted in final form March 22, 2000

Address reprint requests to: Janusz Szymas, M.D., Department of Pathology, University of Medical Sciences, Przybyszewski Street 49, 60-355 Poznan, Poland. email:jszymas@ ampat.amu.edu.pl. 